\title{
Periparturient stocking density affects lying and ruminating behavior and one-week-calf performance of Holstein cows
}

\author{
Mingming Jiang ${ }^{1,2,3, a}$, Gibson Maswayi Alugongo ${ }^{2, a}$, Jianxin $\mathrm{XiaO}^{2}$, Congcong $\mathrm{Li}^{4}$, \\ Yulin $\mathrm{Ma}^{2}$, Tingting $\mathrm{Li}^{5}$, Zhijun $\mathrm{CaO}^{2, *}$, and Dasen $\mathrm{Liu}^{1, *}$
}

\author{
* Corresponding Authors: \\ Zhijun Cao \\ Tel: $+86-13810382286$ \\ Fax: +86-010-62734080 \\ E-mail: caozhijun@cau.edu.cn \\ Dasen Liu \\ Tel: $+86-13945697905$ \\ Fax: +86-0451-55190114 \\ E-mail: dasenliu@neau.edu.cn
}

${ }^{1}$ College of Animal Science and Technology, Northeast Agricultural University, Harbin 150030, China

${ }^{2}$ College of Animal Science and Technology, State Key Laboratory of Animal Nutrition, China Agricultural University, Beijing 100193, China

${ }^{3}$ College of Animal Science, Heilongjiang Agriculture Economics Vocational College, Mudanjiang 157041, China

${ }^{4}$ State Key Laboratory of Animal Nutrition, Institute of Animal Sciences, Chinese

Academy of Agricultural Sciences, Beijing, 100193, China

${ }^{5}$ College of Animal Science and Technology, Xinjiang Agricultural University, Urumqi 830052, China

a These two authors contributed equally to this work.

ORCID

Mingming Jiang

https://orcid.org/0000-0002-7733-7918

Gibson Maswayi Alugongo

https://orcid.org/0000-0003-3977-6917

Jianxin Xiao

https://orcid.org/0000-0002-3074-5973

Congcong Li

https://orcid.org/0000-0003-2178-6770 Yulin Ma

https://orcid.org/0000-0001-6567-4469

Tingting Li

https://orcid.org/0000-0003-1376-4811

Zhijun Cao

https://orcid.org/0000-0002-5519-9462

Dasen Liu

https://orcid.org/0000-0001-6504-2007

Submitted Mar 1, 2020; Revised Apr 22, 2020 Accepted May 17, 2020
Objective: This study aimed to investigate the effect of stocking density on the behavior, productivity, and metabolism of periparturient Holstein cows as well as calf performance. Methods: A total of 48 periparturient cows were randomly assigned into three groups at 28 days ( \pm 3 days) before their expected calving date. The stocking densities of the groups, relative to the standard cubicle and feed bunk number, were i) $80 \%$ (13 cows), ii) $100 \%$ (16 cows), and iii) $120 \%$ (19 cows). Lying and rumination behavior was recorded using electronic data loggers and HR-Tags from d -21 ("d-" means days before calving) until the calving date, $\mathrm{d} 0$. Lying time was assessed to determine the diurnal total hours spent lying per day. Rumination time was averaged in 2 hours interval periods over 24 hours during the experimental period.

Results: Cows in the $80 \%$ group spent more time lying and ruminating between $\mathrm{d}-21$ and $\mathrm{d}-7$ and tended to ruminate more between $\mathrm{d}-14$ and $\mathrm{d} 0$. Calcium levels tended to be higher for cows in the $80 \%$ group, no other observable differences were found in monitored blood parameters. Moreover, $3.5 \%$ fat corrected milk and energy corrected milk yields were higher in $80 \%$ group in the first month of lactation. No other observable differences were found in the yield and composition of colostrum and milk in the first 10 months of lactation. The growth and performance of calves in the first week of life was not affected by stocking density of the dams.

Conclusion: We concluded that lower stocking density may increase lying and ruminating behavior of prepartum Holstein cows. However, this did not translate into improved productivity and metabolism.

Keywords: Peripartum Dairy Cow; Stocking Density; Behavior; Productivity; Metabolism

\section{INTRODUCTION}

During the transition from gestation to lactation, dairy cows experience several social stressors including regrouping and nutritional changes. If these stressors are not managed well, they could exacerbate the incidences of metabolic diseases immediately after parturition in cows [1]. Overstocking is frequently practiced on large modern dairy farms with intensive farming systems [2]. High stocking density may escalate competition at the feed bunk, increase disease incidences and impact cow welfare [3], thus resulting in lower profit margins for farmers [2].

The recommended stocking density during the prepartum period is at least one cubicle of resting space per cow [4]. Various studies have observed that elevated stocking density ( $200 \%$ vs $100 \%$ cow to feed bunk) and feed bunk space (30 vs $60 \mathrm{~cm} / \mathrm{cow}$ ) may result in increased standing time, rate of feeding displacement, and feed sorting behavior, as well as decreased overall feed intake [5,6]. It is also reported that cows will typically occupy $80 \%$ 
of the feed bunk space during the peak feeding time after fresh feed delivery [7]. Since adequate feed intake is a prerequisite for healthy post-partum cows, the observed behaviors are likely to affect post-parturition physiology. Monitored lying time has been suggested as a marker of cow comfort. Recently, a large scale study suggested that lying time along with energy and calcium (Ca) levels were critical for transition cows [8]. Notably, blood parameters, such as nonesterified fatty acids (NEFA), indicate the health of Holstein cows $[8,9]$. Additional controlled studies are needed to understand better the effects of stocking density stress in transition cows.

Prepartum management may not only affect the cow and its health, but it can also have detrimental effects on in utero calf development, with almost $60 \%$ of calf growth happening in the third trimester. Although studies on stocking density are on the increase, research regarding the in utero environment of cows are scarce. A few studies on nutrition and heat stress have indicated that calves are affected by pre-partum cow management [10]. It remains to be determined whether such deleterious effects can be extended to stocking density or not. This is because stocking density experiments are difficult to conduct owing to the dynamics of the sample size, especially around calving when cows are usually replaced to keep the original density $[9,11]$. Moreover, the influence of stocking density on cow behavioral patterns and the performance of their progeny is still unclear. The objective of this study was to determine whether the stocking density could impact the behavior, productivity and metabolism of prepartum Holstein cows or not, and to investigate the role stocking density plays on the colostrum quality as well as the performance of one week old calves.

\section{MATERIALS AND METHODS}

\section{Animals, treatment and management}

All the experimental protocols followed in this study were approved by the Institutional Animal Care and Use Committee of the China Agricultural University (Beijing, China). The experiment was conducted between December 2017 and January 2018. In total, 48 multiparous prepartum Holstein cows (dried off $\mathrm{d} 60$ before expected calving date) were selected and randomly assigned into three pens $(20 \mathrm{~m}$ long and $12.8 \mathrm{~m}$ width) at 4 weeks ( $\mathrm{d} 28 \pm 3$ ) before parturition. All the selected cows were entering the 2 nd to the 4 th lactation based on their proximity to their calving dates from a dry off group of 300 cows at Zhongdi Farm in Beijing, a commercial farm with 4,500 heads of dairy cattle. Each pen was assigned to one of the three treatments and balanced for parity (2.8 \pm 0.1$)$, previous milk yield $(37.0 \pm 6.2 \mathrm{~kg} / \mathrm{d})$, and body weight (BW, 797.6 $\pm 71.3 \mathrm{~kg}$ ). Cows were weighed on $\mathrm{d}-21$ ("d-" means days before calving) and $\mathrm{d} 1$ ("d" means days after calving) relative to parturition. Cows had a similar body condition score (BCS) of between 3 and 5 (average $3.25 \pm 0.25 ; 1$ to 5 scale; $1=$ emaciated, $5=$ obese) and a locomotion score of under 2 ( 1 to 5 scale; $1=$ normal gait, $5=$ severely lame) at the time of enrollment [12]. In each pen, there were 16 cubicles (head to head water beds, $2.40 \mathrm{~m}$ long $\times 1.20 \mathrm{~m}$ wide; Advanced Comfort Technology Inc., Sun Prairie, WI, USA) and 16 feed bunks (1.00 m widex $0.75 \mathrm{~m}$ high $\times 0.84 \mathrm{~m}$ depth; Roughage Intake Control System, Insentec B.V, Marknesse, the Netherlands).

The stocking density of the three treatments were calculated as the number of cows relative to the cubicle and feed bunk number, which were: i) $80 \%$ (13 cows), ii) 100\% (16 cows), and iii) $120 \%$ (19 cows). One thermostatic water trough $(366 \times 56 \mathrm{~cm})$ with two watering openings was available in each pen. The feed alleys and back alleys were $4.25 \mathrm{~m}$ and $3.70 \mathrm{~m}$ in width, respectively. The floor was scraped with an automatic scraper system (GEA Farm Technologies, Düsseldorf, Germany). The cubicles were fitted with waterbeds that were resupplied with approximately $10.0 \mathrm{~cm}$ of rice husk once per week. The cows were provided a close up diet (total mixed ration) feed and fresh cow diet (Table 1), pre- and post-parturitiion, respectively. The feed bunks were filled twice daily at 08:00 am and 15:00 pm for ad libitum intake. All cows underwent a daily clinical examination by the farm veterinarian throughout the study period. In addition, the pens were monitored via a video feed in proximity to the pens.

After calving, the cows were transferred to a separate pen for post-calving management and health examination. The cows received a Ca supplement (Bovikalc, Boehringer Ingelheim Vetmedica GmbH, Ingelheim am Rhein, Germany) immediately after calving and received the second Bovikalc $12 \mathrm{~h}$ later. Cows also received an oral administration of Propylene Glycol and Ca-P-Mg (Meilin calcium oral, $500 \mathrm{~mL} /$ bottle; Huataiyuan Pharmaceutical Co., Ltd, Beijing, China) mixture during the $12 \mathrm{~h}$. The calf was moved within $5 \mathrm{~min}$ utes after calving to a newborn calf room. Cows deemed healthy one day post-calving were moved to a free-stall pen with 240 cubicles and 260 headlocks. Calves received $4 \mathrm{~L}$ of colostrum within 1 h of parturition (immunoglobulin $\mathrm{G}>22$ $\mathrm{g} / \mathrm{dL}$ ) as per the farm protocol. Calves were transferred into individual hutches bedded with straw on $\mathrm{d} 1$, just before the first milk feeding, where they were monitored for 7 days after birth. Calves were reared under identical conditions. They received $3 \mathrm{~L}$ of pasteurized waste milk twice daily at 7:00 am and 15:00 pm. BW was recorded immediately after birth and on $\mathrm{d} 7$ using a digital scale. Average daily gain was calculated by dividing the difference between initial BW and final BW by number of days.

\section{Behavioral observation}

Electronic data loggers (HOBO Pendant G, Onset Computer 
Table 1. Ingredient composition and nutrient levels of experimental diets (dry matter, \%)

\begin{tabular}{lcc}
\hline Item & Close-up & Fresh cow diet \\
\hline Ingredient & & \\
Oat hay & 23.72 & - \\
Domestic alfalfa hay & - & 15.99 \\
Imported alfalfa hay & 3.38 & 4.13 \\
whole corn silage & 38.63 & 21.15 \\
Ground corn & 4.85 & 1.95 \\
Corn-steam flaked & - & 20.73 \\
Extruded soybean meal & 1.67 & 2.15 \\
Soybean meal & 9.87 & 11.62 \\
Palm kernel meal & 1.32 & - \\
Soybean hulls & 6.23 & 11.66 \\
Whole cottonseed & 3.28 & 4.00 \\
Molasses & 1.99 & - \\
Premix & 5.06 & 6.62 \\
Total & 100.00 & 100.00 \\
Chemical composition & & \\
CP & 11.89 & 15.42 \\
Crude fat & 3.51 & 4.85 \\
NDF & 38.53 & 31.02 \\
ADF & 23.00 & 20.11 \\
Crude ash & 7.60 & 7.63 \\
Chloride & 0.64 & 0.50 \\
Calcium & 0.63 & 0.92 \\
Phosphorus & 0.31 & 0.41 \\
Magnesium & 0.33 & 0.30 \\
Sodium & 0.31 & 0.44 \\
Potassium & 0.99 & 1.47 \\
Sulfur & 0.11 & 0.14 \\
\hline
\end{tabular}

$C P$, crude protein; NDF, neutral detergent fiber; ADF, acid detergent fiber.

1) The premix provided to dry dairy cow per kg included: Vitamin $A$ 770,000 IU, Vitamin $D_{3}$ 192,500 IU, Vitamin E 7,000 IU, Cu 500 mg, Mn 1,800 mg, Zn 3,000 mg, I 56 mg, Se 19 mg, and Co 64 mg.

The premix provided to fresh cow per kg included: Vitamin A 116,500 IU, Vitamin $D_{3} 57,000$ IU, Vitamin E 750 IU, Fe 1.1 mg, Cu 0.7 mg, Mn 2.2 mg, $176 \mathrm{mg}$, Se $5.5 \mathrm{mg}$ and Co $29 \mathrm{mg}$.

Corp., Bourne, MA, USA); validated by Ledgerwood et al [13] were placed on the right hind leg of prepartum cows at 22 days before expected date of parturition and removed immediately after calving to assess the lying time. The loggers were frequently checked to ensure they were well fastened on the leg. Data from individual animals were exported from the HOBO ware Pro software to an excel spreadsheet (Microsoft Corp., Redmond, WA, USA). Lying time was summarized to determine the diurnal total number of hours spent lying in a day. Rumination time was assessed with HR-Tags (SCR Engineers Ltd., Netanya, Israel) that were fitted to the left side of the neck of each cow from day of enrollment (d -28) to calving ( $\mathrm{d} 0$ ) of each experimental animal and averaged in $2 \mathrm{~h}$ interval periods over $24 \mathrm{~h}$.

\section{Colostrum and milk parameters}

After calving, colostrum yield (the first time milking after calving) was recorded. The total protein (TP) of colostrum was tested by the PAL- 1 type digital Brix refractometer (ATAGO, Bellevue, WA, USA) and $\mathrm{pH}$ was analyzed by a portable $\mathrm{pH}$ meter (LAQUA twin, Horiba Scientific, Edison, NJ, USA). Cows were milked thrice daily. Milk yield of each cow was collected on day 15 and every 15th day of the month thereafter, post-calving and averaged as the daily milk yield. Subsequently, milk samples were collected from three time milking points and then mixed (4:3:3, composite from each daily milking) for the analysis of milk composition (Dairy Products Quality Supervision and Inspection Center, Beijing, China) such as fat, protein, lactose, and urea nitrogen using a Combi Foss FT+ instrument (Foss Electric, Hillerød, Denmark). Somatic cell counts (SCC) were analyzed by a Fossomatic 5000 apparatus (Foss Electric, Denmark). Fatcorrected milk yield (FCM) was calculated using the equation: $0.432 \times$ milk yield $(\mathrm{kg} / \mathrm{d})+16.23 \times$ milk fat yield $(\mathrm{kg} / \mathrm{d})$; and the energy corrected milk yield (ECM) was calculated based on the following equation: $0.327 \times$ milk yield $(\mathrm{kg} / \mathrm{d})+12.95 \times$ milk fat yield $(\mathrm{kg} / \mathrm{d})+7.2 \times$ milk protein yield $(\mathrm{kg} / \mathrm{d})$.

\section{Blood parameters}

Blood samples were collected from the coccygeal vein on $\mathrm{d}$ $-7,0,1$, and 7 relative to the expected calving date for all cows and on $\mathrm{d} 0,1$, and 7 of age from the jugular vein for the calves. All blood samples were collected into vacuum blood collection tubes (Vacutainer, Becton Dickinson, Franklin Lakes, NJ, USA) containing no anticoagulant. The blood sampling time for both dairy cows and calves was approximately 6:00 am before the morning feeding, except for $\mathrm{d} 0$ which was sampled right after calving and before colostrum feeding for cows and calves, respectively. The blood was centrifuged at $2,400 \times \mathrm{g}$ for $15 \mathrm{~min}$ at $4^{\circ} \mathrm{C}$. The serum was stored at $-20^{\circ} \mathrm{C}$ in a freezer until analysis.

The samples were analyzed using commercially available kits according to manufacturer's instructions. The concentration of cortisol (COR), total cholesterol (TC), triglycerides (TG), TP, NEFA, $\beta$-hydroxybutyrate (BHBA), blood urea nitrogen (BUN), and $\mathrm{Ca}$ were determined in the serum. All blood samples were quantified by an automated biochemistry analyzer (Gaomi Caihong Co Ltd, Shandong, China) except for COR that was measured by a multichannel radioimmunecounter (Zhongcheng Mechanical and Electrical Technology Co Ltd, Hefei, China). In calves, COR, BUN, and TP were determined, with TP being measured by a handheld optical refractometer.

\section{Rumen fermentation parameters}

Rumen fluid was collected using an oral stomach tubing $4 \mathrm{~h}$ after cows had had their morning feed on $\mathrm{d}-15,-7$, and 7 relative to parturition. The first $(150 \mathrm{~mL})$ was discarded to avoid saliva contamination. The rumen $\mathrm{pH}$ level was imme- 
diately measured, and $50 \mathrm{~mL}$ of each sample was immediately stored at $-20^{\circ} \mathrm{C}$ for further analysis. Samples were analyzed for total volatile fatty acids (VFA), proportions of acetate, propionate, butyrate. valerate, isobutyrate, isovalerate, and ammonia.

\section{Statistical analysis}

Ten cows per treatment were chosen for analysis purposes. All statistical analyses were performed using MIXED procedure of SAS (SAS Institute Inc., Cary, NC, USA). Continuous variables with repeated measurements including lying and ruminating behavior, the plasma and ruminal fermentation parameters were analyzed with the fixed effects of treatment, day of measurement, interaction between treatment and day of measurement, and the random effect of cow or calf nested within treatment. Variables with a single measurement during the study, such as milk production and composition, average calving date and colostrum quality were analyzed with the fixed effects of treatment of cow and the random effect of cow nested within treatment. It should be noted that feed intake data is excluded due to the technical issues experienced with the feeder. All treatment results are reported as least squares means. Significant differences were declared at $\mathrm{p} \leq 0.05$ and tendencies at $\mathrm{p} \leq 0.10$.

\section{RESULTS}

\section{Feeding and behavior}

The behavioral results of lying and ruminating are reported in Table 2 and Figure 1. Cows in the $80 \%$ stocking density group spent more time lying $(\mathrm{p}<0.05)$ and ruminating $(\mathrm{p}<$ 0.03 ) compared to cows in both the $100 \%$ and $120 \%$ groups. This finding was more apparent on $\mathrm{d}-21$ and $\mathrm{d}-14$ relative to parturition. Ruminating time tended to be significantly different on $\mathrm{d}-14$ and $\mathrm{d}-7$ relative to parturition $(\mathrm{p}<0.10)$.

\section{Colostrum and milk}

The average yield, composition and quality of colostrum and milk are listed in Table 3 and 4 . No differences were observed in the overall colostrum and milk yield, colostrum (TP), and milk (milk fat, milk protein, milk urea nitrogen and lactose) composition and quality (SCC and pH). However, a significant effect was observed for milk yield, FCM and ECM ( $p=$ 0.01 ) in the first month of lactation (data not shown) with the $80 \%$ group cows having greater yields.

\section{Blood parameters}

The effect of stocking density on blood parameters in transition cows (Table 5; Figure 2) and calves (Table 6; Figure 3)

Table 2. Effect of different stocking densities on lying and ruminating time of studied cows during 21 days before calving

\begin{tabular}{|c|c|c|c|c|c|c|c|}
\hline \multirow{2}{*}{ Item } & \multicolumn{3}{|c|}{ Stocking density (\%) } & \multirow{2}{*}{ SEM } & \multicolumn{3}{|c|}{ p-value ${ }^{1)}$} \\
\hline & 80 & 100 & 120 & & Trt & Time & $T \times T$ \\
\hline Lying time (h/d) & $12.5^{a}$ & $11.3^{b}$ & $11.0^{\mathrm{b}}$ & 0.39 & 0.05 & $<0.01$ & 0.70 \\
\hline
\end{tabular}

Statistical analysis were carried out using MIXED procedure of SAS (SAS Institute Inc., Cary, NC, USA).

SEM, standard error of mean; Trt, treatment; $T \times T$, treatment by time interaction.

1) $p<0.05$ means a significant effect; $p<0.10$ means a tended effect.

$a, b$ Values within same row with different superscripts mean significant difference $(p<0.05)$.
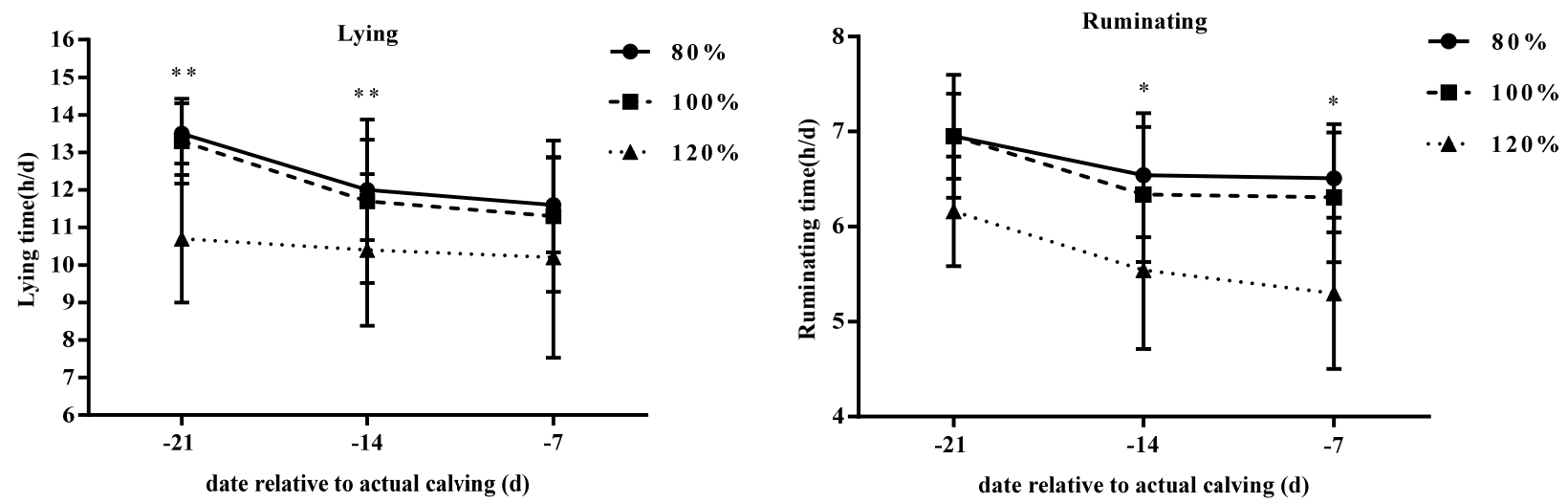

Figure 1. Effect of different feeding density on lying time and ruminating time. During the prepartum period ( $\mathrm{d}-21$ to -7 before calving). Lying and rumination behavior was recorded using electronic data loggers and HR-Tags from. Lying time was assessed to determine the diurnal total hours spent lying per day. Rumination time was averaged in 2 hours interval periods over 24 hours during the experimental period. Different periparturi-

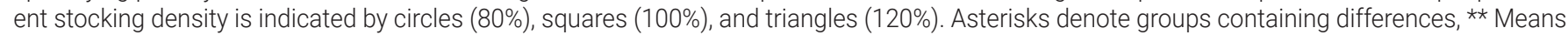
a significant effect $(p<0.05)$, * means a tendency of effect $(p<0.10)$. 
Table 3. Effect of different stocking densities on milk production and composition

\begin{tabular}{|c|c|c|c|c|c|c|c|}
\hline \multirow{2}{*}{ Item } & \multicolumn{3}{|c|}{ Stocking density (\%) } & \multirow{2}{*}{ SEM } & \multicolumn{3}{|c|}{ p-value ${ }^{1)}$} \\
\hline & 80 & 100 & 120 & & Trt & Time & $T \times T$ \\
\hline Milk yield & 27.2 & 26.3 & 26.8 & 1.42 & 0.91 & $<0.01$ & 0.47 \\
\hline $3.5 \% \mathrm{FCM}^{2)}$ & 28.8 & 26.7 & 26.6 & 1.38 & 0.47 & $<0.01$ & 0.36 \\
\hline $\mathrm{ECM}^{3)}$ & 29.5 & 27.5 & 27.8 & 1.42 & 0.58 & $<0.01$ & 0.39 \\
\hline Fat $(\%)$ & 3.86 & 3.72 & 3.48 & 0.12 & 0.06 & $<0.01$ & 0.08 \\
\hline Protein (\%) & 3.59 & 3.63 & 3.61 & 0.48 & 0.84 & $<0.01$ & $<0.01$ \\
\hline Lactose (\%) & 5.00 & 4.92 & 4.97 & 0.43 & 0.39 & $<0.01$ & 0.45 \\
\hline Mun (mg/dL) & 15.3 & 14.9 & 14.9 & 0.37 & 0.71 & $<0.01$ & 0.20 \\
\hline $\operatorname{SCC}(1,000 / \mathrm{mL})$ & 216.1 & 290.1 & 272.0 & 69.8 & 0.75 & 0.01 & 0.97 \\
\hline
\end{tabular}

SEM, standard error of mean; Trt, treatment; T×T, Treatment by time interaction; FCM, fat corrected milk; ECM, energy corrected milk; SCC, somatic cell count.

1) $p<0.05$ means a significant effect; $p<0.10$ means a tendency of effect (MIXED procedure of SAS [SAS Institute Inc., Cary, NC, USA]).

2) $3.5 \% \mathrm{FCM}=0.432 \times$ milk yield $(\mathrm{kg} / \mathrm{d})+16.23 \times$ milk fat yield $(\mathrm{kg} / \mathrm{d})$.

${ }^{3)} \mathrm{ECM}=0.327 \times$ milk yield $(\mathrm{kg} / \mathrm{d})+12.95 \times$ milk fat yield $(\mathrm{kg} / \mathrm{d})+7.2 \times$ milk protein yield $(\mathrm{kg} / \mathrm{d})$.

Table 4. Effect of different stocking densities on average calving date and colostrum quality and volume

\begin{tabular}{|c|c|c|c|c|c|}
\hline \multirow{2}{*}{ Item } & \multicolumn{3}{|c|}{ Stocking density (\%) } & \multirow{2}{*}{ SEM } & \multirow{2}{*}{$\frac{\text { p-value }}{\text { Trt }}$} \\
\hline & 80 & 100 & 120 & & \\
\hline ACD & 280.1 & 282.8 & 281.4 & 1.0 & 0.16 \\
\hline Brix & 25.4 & 27.1 & 27.2 & 1.1 & 0.50 \\
\hline Weight & 5.13 & 4.09 & 5.65 & 1.1 & 0.56 \\
\hline
\end{tabular}

SEM, standard error of mean; Trt, treatment; ACD, average calving date.

are reported. The stocking density was found to relate to $\mathrm{Ca}$ levels $(\mathrm{p}=0.07)$, but no other observable effect on the blood parameters was measured. The COR, TC, TG, TP, BUN, and Ca were affected by time $(\mathrm{p}<0.05)$. Meanwhile, treatment $x$ time interactions were absent in these parameters, except for $a$ trend in TG $(\mathrm{p}<0.09)$ and NEFA $(\mathrm{p}<0.08)$. These observations could be attributed to higher concentrations in TG on $\mathrm{d}-7$ in the $120 \%$ group and lower concentrations of NEFA on $\mathrm{d} 0$ for the $80 \%$ group. No time effect was observed in NEFA and BHBA in this study. In calves, COR, BUN, Ca, and TP were not different between groups at any of the days sampled. However, COR and TP changed with time $(\mathrm{p}<0.05)$.

\section{Rumen fermentation parameters}

The proportions of total VFA, acetate, propionate, butyrate, valerate, Isobutyrate, and isovalerate concentrations as well as acetate/propionate ratio, ammonia nitrogen and $\mathrm{pH}$ are reported in Table 7 and Figure 4. There were no treatment or treatment by time effects detected in this trial. Only acetate, valarate, isobutyrate, isovalarate, and ammonia nitrogen changed with time $(\mathrm{p}<0.05)$. Concentration of acetate and ammonia nitrogen decreased as the cows approached parturition, while, valerate, isobutyrate, and isovalarate increased. Post-parturition the reverse happened. Ruminal $\mathrm{pH}$ was also similar between groups but changed with time $(\mathrm{p}<0.01)$.

\section{Body weight and structural measurements for calves} The BW, body length, withers height, breast circumference and abdominal circumference are shown in Table 8. There were no differences between $\mathrm{d} 1$ and 7 after birth in all the parameters, but the calves increased in BW during this time period $(\mathrm{p}<0.01)$.

Table 5. Effect of different stocking densities on blood parameters of transition cows

\begin{tabular}{|c|c|c|c|c|c|c|c|}
\hline \multirow{2}{*}{ Item } & \multicolumn{3}{|c|}{ Stocking density (\%) } & \multirow{2}{*}{ SEM } & \multicolumn{3}{|c|}{ p-value ${ }^{1)}$} \\
\hline & 80 & 100 & 120 & & Trt & Time & $\mathrm{T} \times \mathrm{T}$ \\
\hline NEFA $(\mu \mathrm{mol} / \mathrm{L})$ & 62.6 & 67.9 & 70.8 & 5.1 & 0.55 & 0.86 & 0.08 \\
\hline $\mathrm{BHBA}(\mathrm{mmol} / \mathrm{L})$ & 0.56 & 0.60 & 0.58 & 0.54 & 0.86 & 0.86 & 0.33 \\
\hline $\mathrm{TG}(\mathrm{mmol} / \mathrm{L})$ & 0.31 & 0.29 & 0.33 & 0.02 & 0.20 & $<0.01$ & 0.09 \\
\hline $\mathrm{TC}(\mathrm{mmol} / \mathrm{L})$ & 2.29 & 2.05 & 2.13 & 0.19 & 0.68 & $<0.01$ & 0.21 \\
\hline $\mathrm{TP}(\mathrm{g} / \mathrm{L})$ & 72.2 & 72.6 & 70.1 & 1.1 & 0.23 & 0.02 & 0.31 \\
\hline BUN (mmol/L) & 3.25 & 3.74 & 3.23 & 0.32 & 0.44 & $<0.01$ & 0.86 \\
\hline $\mathrm{Ca}(\mathrm{mmol} / \mathrm{L})$ & 2.01 & 1.85 & 1.92 & 0.46 & 0.07 & 0.05 & 0.61 \\
\hline $\mathrm{COR}(\mathrm{ng} / \mathrm{mL})$ & 18.6 & 20.3 & 19.1 & 2.1 & 0.85 & $<0.01$ & 0.55 \\
\hline
\end{tabular}

SEM, standard error of mean; Trt, treatment; T×T, treatment by time interaction; NEFA, non-esterified fatty acids, BHBA, $\beta$-hydroxybutyric acid; TG, triglycerides; TC, total cholesterol; TP, total protein; BUN, blood urea nitrogen; $\mathrm{Ca}$, calcium; COR, cortisol.

${ }^{1)} p<0.05$ means a significant effect; $p<0.10$ means a tendency of effect (MIXED procedure of SAS [SAS Institute Inc., Cary, NC, USA]). 

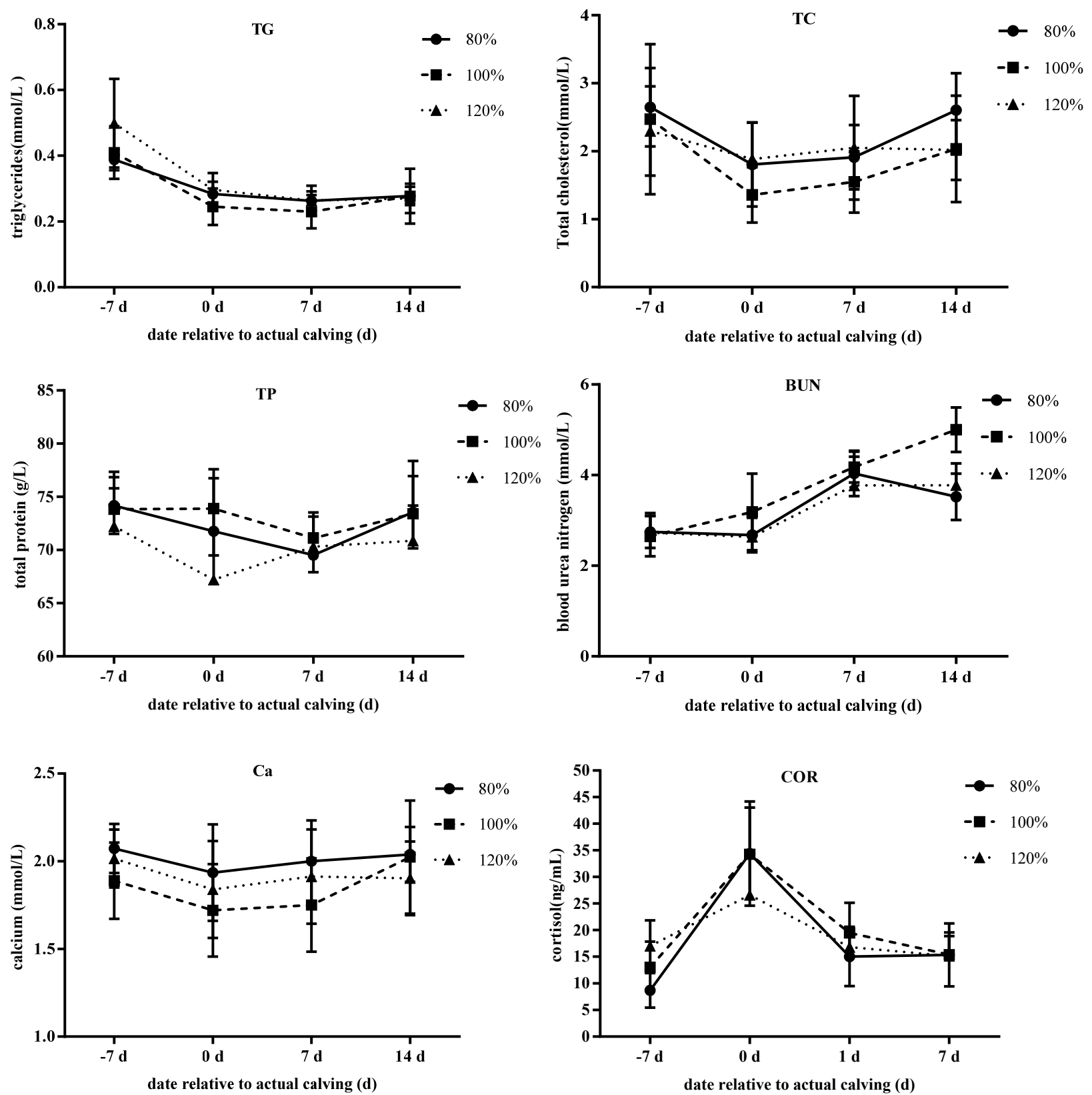

Figure 2. Effect of different stocking densities on blood parameters of transition cows. Blood samples were collected from the coccygeal vein on $d-7,0,1$ and 7 relative to the expected calving date for all cows. All blood samples were collected into vacuum blood collection tubes. Different periparturient stocking density is indicated by circles ( $80 \%)$, squares (100\%), and triangles (120\%). TG, triglycerides; TC, total cholesterol, TP, total protein; BUN, blood urea nitrogen; Ca, calcium; COR, cortisol.

Table 6. Effect of different stocking densities on blood parameters of newborn calves

\begin{tabular}{|c|c|c|c|c|c|c|c|}
\hline \multirow{2}{*}{ Item } & \multicolumn{3}{|c|}{ Stocking density (\%) } & \multirow{2}{*}{ SEM } & \multicolumn{3}{|c|}{ p-value ${ }^{1)}$} \\
\hline & 80 & 100 & 120 & & Trt & Time & $T \times T$ \\
\hline COR (ng/Ml) & 58.3 & 65.8 & 61.0 & 3.8 & 0.35 & $<0.01$ & 0.28 \\
\hline BUN, (mmol/L) & 3.14 & 2.89 & 3.20 & 0.24 & 0.59 & 0.22 & 0.48 \\
\hline $\mathrm{Ca},(\mathrm{mmol} / \mathrm{L})$ & 1.88 & 1.99 & 2.12 & 0.81 & 0.15 & 0.51 & 0.54 \\
\hline $\mathrm{TP}(\mathrm{g} / \mathrm{dL})$ & 5.43 & 5.41 & 5.45 & 0.14 & 0.97 & $<0.01$ & 0.24 \\
\hline
\end{tabular}

SEM, standard error of mean; Trt, treatment; TxT, treatment by time interaction; COR, cortisol; BUN, blood urea nitrogen; Ca, calcium; TP, total protein. ${ }^{1)} p<0.05$ means a significant effect; $p<0.10$ means a tendency of effect (MIXED procedure of SAS [SAS Institute Inc., Cary, NC, USA]). 

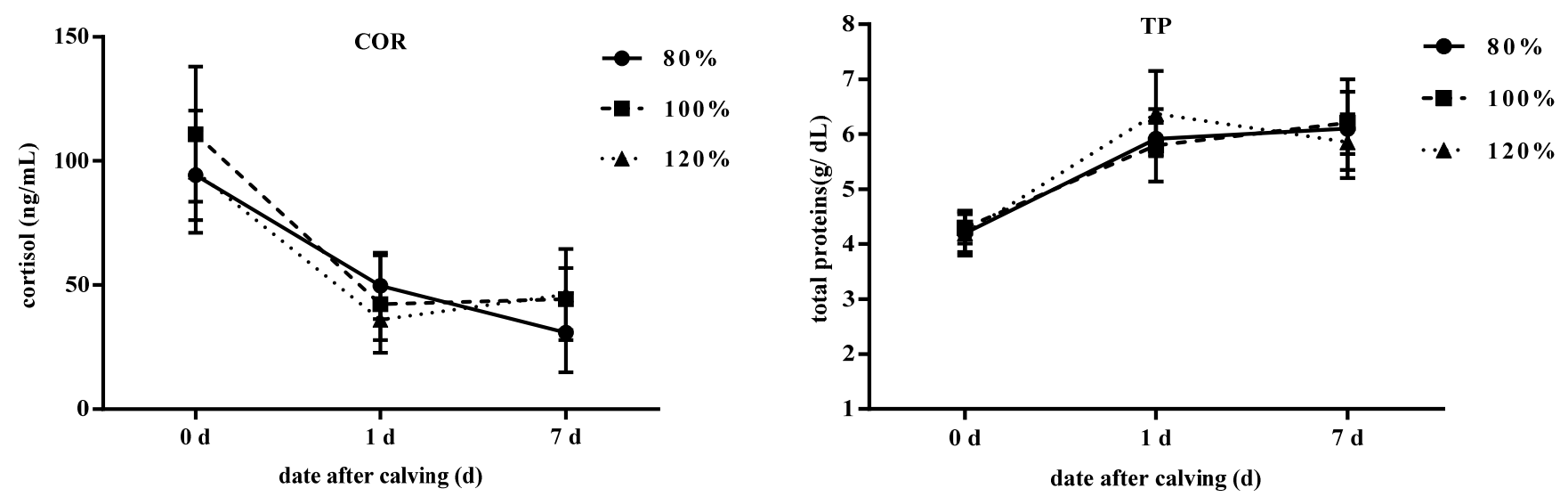

Figure 3. Effect of different stocking densities on blood parameters of newborn calves. Blood samples were collected from the jugular vein on d 0 , 1 , and 7 of age for the calves. All blood samples were collected into vacuum blood collection tubes containing no anticoagulant. Different periparturient stocking density is indicated by circles (80\%), squares (100\%), and triangles (120\%). COR, cortisol; TP, total protein.

Table 7. Effect of different stocking densities on ruminal fermentation parameters in cows before and after calving

\begin{tabular}{|c|c|c|c|c|c|c|c|}
\hline \multirow{2}{*}{ Item } & \multicolumn{3}{|c|}{ Stocking density (\%) } & \multirow{2}{*}{ SEM } & \multicolumn{3}{|c|}{ p-value ${ }^{1)}$} \\
\hline & 80 & 100 & 120 & & Trt & Time & $\mathrm{T} \times \mathrm{T}$ \\
\hline Total VFA (mmol/L) & 99.53 & 100.08 & 99.82 & 2.86 & 0.87 & 0.10 & 0.56 \\
\hline Acetate proportion (\%) & 58.3 & 57.7 & 57.3 & 1.61 & 0.90 & 0.03 & 0.83 \\
\hline Propionate proportion (\%) & 23.4 & 25.5 & 25.2 & 1.2 & 0.45 & 0.90 & 0.77 \\
\hline Butyrate proportion (\%) & 9.17 & 9.45 & 9.18 & 0.50 & 0.90 & 0.16 & 0.34 \\
\hline Valerate proportion (\%) & 2.11 & 1.8 & 1.91 & 0.11 & 0.35 & 0.02 & 0.54 \\
\hline IsoButyrate proportion (\%) & 2.66 & 2.69 & 2.52 & 0.46 & 0.95 & 0.01 & 0.42 \\
\hline IsoValerate proportion (\%) & 3.89 & 2.94 & 3.71 & 0.64 & 0.55 & 0.01 & 0.45 \\
\hline Acetate/propionate & 5.12 & 4.9 & 4.78 & 0.15 & 0.71 & 0.55 & 0.49 \\
\hline Ammonia nitrogen & 10.92 & 12.32 & 11.76 & 0.99 & 0.60 & 0.01 & 0.98 \\
\hline $\mathrm{pH}$ & 6.71 & 6.67 & 6.77 & 0.05 & 0.33 & $<0.01$ & 0.27 \\
\hline
\end{tabular}

SEM, standard error of mean; Trt, treatment; $T \times T$, treatment by time interaction; VFA, volatile fatty acid.

${ }^{1)} p<0.05$ means a significant effect; $p<0.10$ means a tendency of effect (MIXED procedure of SAS [SAS Institute Inc., Cary, NC, USA])

\section{DISCUSSION}

\section{Behavioral measures}

In this study, the results indicated that lying and rumination behavior can be affected by stocking density in the last 21 days of pregnancy of Holstein cows. Specifically, understocked cows (80\% group) spent more time lying and ruminating compared to the other two groups (100\% and $120 \%$ groups).
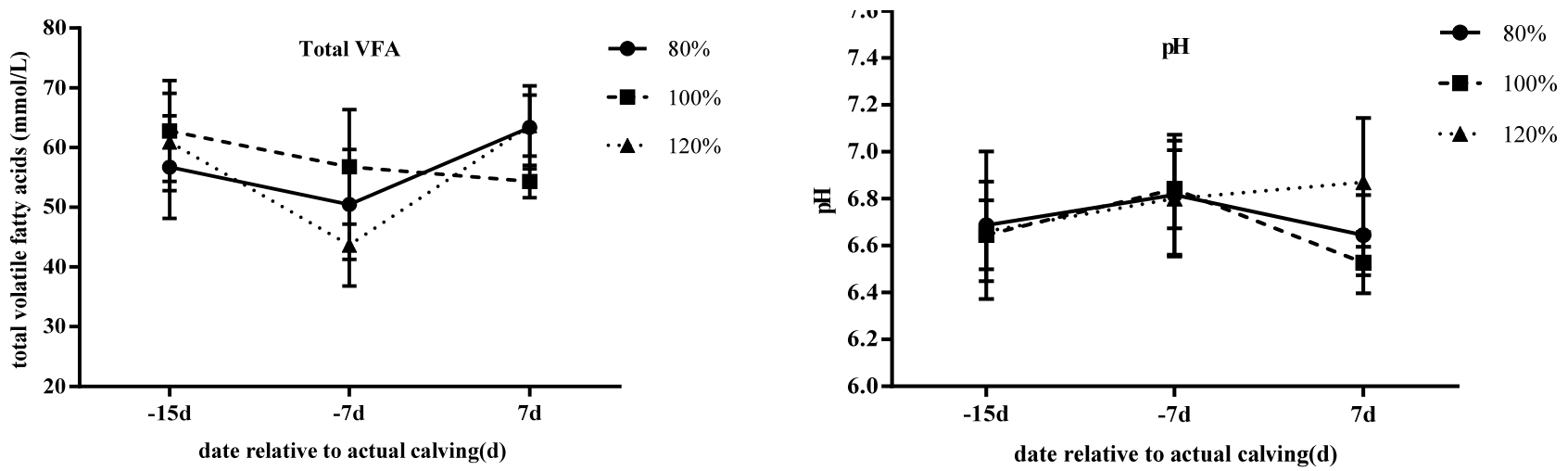

Figure 4. Effect of different stocking densities on total volatile fatty acid (TVFA) and pH of transition cows. Rumen fluid was collected using an oral stomach tubing $4 \mathrm{~h}$ after cows had had their morning feed on $\mathrm{d}-15,-7$, and 7 relative to parturition. Different periparturient stocking density is indicated by circles (80\%), squares (100\%), and triangles (120\%). 
Table 8. Effect of different stocking densities on birth body weight and structural measurement

\begin{tabular}{|c|c|c|c|c|c|c|c|}
\hline \multirow{2}{*}{ Item } & \multicolumn{3}{|c|}{ Stocking density (\%) } & \multirow{2}{*}{ SEM } & \multicolumn{3}{|c|}{ p-value $e^{1)}$} \\
\hline & 80 & 100 & 120 & & Trt & Time & $T \times T$ \\
\hline Body weight (kg) & 39.6 & 42.5 & 40.5 & 1.3 & 0.30 & $<0.01$ & 0.56 \\
\hline d 1 & 39.0 & 41.2 & 40.0 & 1.8 & 0.59 & - & - \\
\hline d 7 & 40.4 & 43.6 & 41.0 & 1.2 & 0.15 & - & - \\
\hline Body length (cm) & 73.1 & 72.8 & 71.1 & 1.0 & 0.30 & 0.38 & 0.80 \\
\hline d 1 & 72.7 & 72.1 & 71.1 & 1.5 & 0.74 & - & - \\
\hline $\mathrm{d} 7$ & 73.6 & 73.3 & 71.1 & 1.0 & 0.18 & - & - \\
\hline Withers height (cm) & 76.8 & 76.5 & 77.3 & 0.9 & 0.75 & 0.43 & 0.47 \\
\hline d 1 & 76.1 & 76.9 & 76.6 & 1.2 & 0.90 & - & - \\
\hline d 7 & 77.6 & 76.1 & 77.9 & 1.1 & 0.45 & - & - \\
\hline Breast circumference (cm) & 78.5 & 79.6 & 78.2 & 1.0 & 0.47 & 0.35 & 0.94 \\
\hline d 1 & 78.6 & 80.2 & 78.8 & 1.3 & 0.64 & - & - \\
\hline d 7 & 78.3 & 79.1 & 77.5 & 1.2 & 0.66 & - & - \\
\hline Abdomen circumference (cm) & 80.2 & 80.8 & 79.9 & 1.0 & 0.72 & 0.30 & 0.67 \\
\hline d 1 & 80.1 & 81.9 & 80.6 & 1.4 & 0.65 & - & - \\
\hline$d 7$ & 80.3 & 79.8 & 79.2 & 1.2 & 0.80 & - & - \\
\hline
\end{tabular}

SEM, standard error of mean; Trt, treatment; $T \times T$, treatment by time interaction.

1) $p<0.05$, means a significant effect; $p<0.10$ means a tended effect (MIXED procedure of SAS [SAS Institute Inc., Cary, NC, USA]).

This was more evident from $\mathrm{d}-21$ to $\mathrm{d}-7$. However, the lying time was similar at $d-7$ to $d 0$. These results are in agreement with a previous study [14], which concluded that cows kept in fewer stalls (high stocking density, 150\%) spent less time lying down compared to the control group (stocking density of $100 \%)$. We observed a general decline in lying time among all cows as they approached parturition. Cows tend to be more anxious as they near parturition, hence they will spend more time standing [15]. The average lying times recorded were within established ranges reported in literature. It has also been suggested that parity has an effect on the social behavior of cows [1], hence we selected cows of $\geq 2$ parity, which may have limited greater variation among groups.

Increased stocking density can also result in competition for available space [16] due to allelomimetic behavior, which results in limited time spent lying and eating for some animals [17]. Rumination time tends to decrease as cows approach calving. Increased rumination could be linked to higher resting time reported in this study though this has not been confirmed experimentally [18]. However, our findings demonstrated that rumination was not influenced by the stocking density. More research with larger sample sizes will help clarify the relationship between stocking density, lying time and rumination.

\section{Colostrum and milk yield and quality}

Higher stocking density before parturition has been linked with decreased milk yield in the first 85 days of lactation [19]. However, most studies have reported no difference in milk yield in response to stocking densities before calving [20]. For example, a study on prepartum Holstein cows with two treatments of $80 \%$ cows to stalls and $90 \mathrm{~cm}$ of feeding space per cow (understocked) and 120\% stocking density and 45 $\mathrm{cm}$ of feeding space per cow (overstocked), found no difference in the milk yield and composition for the first 5 weeks postpartum [11]. In our study, we found that milk yield, 3.5\% FCM and ECM was greater for cows in $80 \%$ stocking density in the first month than that in 100\% and 120\% stocking density. The different stocking density during the prepartum period had no effect on the yield and quality of milk from the second month of lactation.

\section{Blood parameters in cows and calves}

During the transition from late gestation to lactation, changes in the endocrinal system as well as feed intake are expected, which can affect metabolic status. By around 10 days before parturition, the NEFA concentration begins to rise in the blood irrespective of the decrease in dry matter intake [21]. In an all-in-all-out entry of cows, where agonistic behavior may result in reduced feed intake compared to traditional weekly entry, NEFA and BHBA concentrations did not differ between groups [22]. The lack of change in NEFA and BHBA levels is notable, although some previous research has shown that these metabolites can remain unchanged until very close to calving date [20]. Hormone concentrations that support gluconeogenesis and adipose tissue mobilization change in an effort to provide enough energy for the fetus and the developing mammary gland $[23,24]$. Lack of change in the blood parameters suggests similar energy status between the experimental groups, while changes in NEFA concentrations could be attributed to the short window of sampling ( $\mathrm{d}-7$ to $\mathrm{d}$ 7). Both BHBA and TG are the end products of non-oxidized fatty acids. Concentrations of TG tended towards significance, which is related to treatment $\times$ time. 
Increased TG is associated with higher concentrations of NEFA in the serum, and may accumulate in liver when greater amounts of NEFA are released from the adipose tissue [24]. However, thresholds at which TG begins to affect other hepatic processes are not clear [24]. We did not observe greater clinical signs in the cows included in this analysis, which may have contributed to the observed metabolic changes. The serum concentrations recorded in this study were lower compared to a previous study conducted in the same facility [25] as well as experiments with similar low protein diets prepartum [26,27].

Under non-inflammatory conditions $\mathrm{Ca}$ is under hormonal control [24]. We found that the understocked (80\%) cows tended to have higher blood Ca levels compared to the other groups (100\% and 120\%). Other studies have also found that cows that were stocked at $120 \%$ had lower Ca compared to those stocked at $80 \%$ [17]. For periparturient dairy cows at the onset of lactation, there is a large increase in mineral losses due to the high mineral requirement for lactogenesis and colostrogenesis and this could result in a decrease in blood Ca concentration. Therefore, we conclude that the $80 \%$ cows might have slightly better Ca homeostatic mechanisms which retained higher blood Ca level than the other groups. The COR is an important marker of stress in animals and tends to increase on the day of parturition. Previous studies have reported no effect on COR concentrations in blood or hair for cows under different stocking densities [28]. Late gestation metabolic stress is likely to affect the immune function, susceptibility to diseases and growth rates of dairy calves [10]. A recent review, concluded that, as long as feed, water and resting space are sufficient and competition is minimized, the immune function, metabolic status, and performance may not be negatively affected [29]. Although, feed and water intake were not measured in this experiment, the differences in lying time may not be significant enough to induce immunological and metabolic disruption resulting in differential measures and health issues.

For successful passive immunity in calves, the serum TP should exceed $5.2 \mathrm{~g} / \mathrm{dL} 24 \mathrm{~h}$ after colostrum feeding. All calves had greater than $5.4 \mathrm{~g} / \mathrm{dL}$ of TP, indicative of successful passive transfer of immunity. The COR is usually high in newborn calves, and decreases with age as observed in this study. The Ca and BUN were within concentrations reported elsewhere for 1 week old calves.

\section{Calf growth parameters}

The BW and structural measurements of calves were also similar between treatments in this study. Similar BW of new born calves were reported in another study of cows under different stocking densities simulated by introducing new animals to the experimental group [28]. The calves had increased BW by $1 \mathrm{~kg}$ at $\mathrm{d} 7$. Growth rates in calves can be expected to be low in this period. Similar to BW there were no differences in the other body measurements between groups.

\section{Rumen fermentation parameters}

The VFA concentration and $\mathrm{pH}$ level were not different between groups at the selected days of sampling. However, the proportion of acetate, valerate, isobutyrate isovalerate changed with time. During the transition period, farmers often change animal diets from dry-off to a fresh diet. In our experiment, cows were introduced to a lactating diet which is high in concentrates compared to the dry-off diet. Hence, the observed decrease in acetate could be associated with the change in diet from a high to low-fiber diet. The observed levels in total VFA is likely a response to greater organic matter available for rumen fermentation [30]. However, as in most other parameters investigated in this trial, no differences were observed between treatments.

\section{CONCLUSION}

This study demonstrated that prepartum stocking density affected the lying and ruminating time from $\mathrm{d}-21$ to $\mathrm{d}-7$ relative to parturition. Cows in the $80 \%$ stocking density group were associated with greater lying and ruminating times compared to the other groups. However, the differences were not significant enough to result in changes in the metabolic status a week before and after parturition. Furthermore, calf growth and performance were not affected in the first week of life.

\section{CONFLICT OF INTEREST}

We certify that there is no conflict of interest with any financial organization regarding the material discussed in the manuscript.

\section{ACKNOWLEDGMENTS}

This research was funded by Key Technologies R\&D Program of China (2016YFD0500507, Beijing, China). The authors thank the Dairy Teaching and Research Farm (Shunyi, Beijing, China) for providing facilities and caring for the cows.

\section{REFERENCES}

1. Jensen MB, Proudfoot KL. Effect of group size and health status on behavior and feed intake of multiparous dairy cows in early lactation. J Dairy Sci 2017;100:9759-68. https://doi. org/10.3168/jds.2017-13035

2. Krawczel PD, Lee AR. Lying time and its importance to the 
dairy cow: impact of stocking density and time budget stresses. Vet Clin Food Anim Pract 2019;35:47-60. https://doi.org/10. 1016/j.cvfa.2018.11.002

3. Olofsson J. Competition for total mixed diets fed for ad libitum intake using one or four cows per feeding station. J Dairy Sci 1999;82:69-79. https://doi.org/10.3168/jds.S00220302(99)75210-0

4. Cook NB, Bennett TB, Nordlund KV. Monitoring indices of cow comfort in free-stall-housed dairy herds. J Dairy Sci 2005;88:3876-85. https://doi.org/10.3168/jds.S0022-0302(05) 73073-3

5. Hosseinkhani A, DeVries TJ, Proudfoot KL, Valizadeh R, Veira DM, von Keyserlingk MAG. The effects of feed bunk competition on the feed sorting behavior of close-up dry cows. J Dairy Sci 2008;91:1115-21. https://doi.org/10.3168/ jds.2007-0679

6. Proudfoot KL, Veira DM, Weary DM, von Keyserlingk MAG. Competition at the feed bunk changes the feeding, standing, and social behavior of transition dairy cows. J Dairy Sci 2009; 92:3116-23. https://doi.org/10.3168/jds.2008-1718

7. Huzzey JM, DeVries TJ, Valois P, von Keyserlingk MAG. Stocking density and feed barrier design affect the feeding and social behavior of dairy cattle. J Dairy Sci 2006;89:12633. https://doi.org/10.3168/jds.S0022-0302(06)72075-6

8. Pineiro JM, Menichetti BT, Barragan AA, et al. Associations of pre- and postpartum lying time with metabolic, inflammation, and health status of lactating dairy cows. J Dairy Sci 2019;102:3348-61. https://doi.org/10.3168/jds.2018-15386

9. Huzzey JM, Veira DM, Weary DM, von Keyserlingk MAG. Prepartum behavior and dry matter intake identify dairy cows at risk for metritis. J Dairy Sci 2007;90:3220-33. https:// doi.org/10.3168/jds.2006-807

10.Ling T, Hernandez-Jover M, Sordillo LM, Abuelo A. Maternal late-gestation metabolic stress is associated with changes in immune and metabolic responses of dairy calves. J Dairy Sci 2018;101:6568-80. https://doi.org/10.3168/jds.2017-14038

11.Silva PRB, Dresch AR, Machado KS, et al. Prepartum stocking density: effects on metabolic, health, reproductive, and productive responses. J Dairy Sci 2014;97:5521-32. https://doi. org/10.3168/jds.2014-8093

12.Lobeck-Luchterhand KM, Silva PRB, Chebel RC, Endres MI. Effect of stocking density on social, feeding, and lying behavior of prepartum dairy animals. J Dairy Sci 2015;98: 240-9. https://doi.org/10.3168/jds.2014-8492

13.Ledgerwood DN, Winckler C, Tucker CB. Evaluation of data loggers, sampling intervals, and editing techniques for measuring the lying behavior of dairy cattle. J Dairy Sci 2010;93: 5129-39. https://doi.org/10.3168/jds.2009-2945

14. Fregonesi JA, Tucker CB, Weary DM. Overstocking reduces lying time in dairy cows. J Dairy Sci 2007;90:3349-54. https:// doi.org/10.3168/jds.2006-794

15. Telezhenko E, von Keyserlingk MAG, Talebi A, Weary DM.
Effect of pen size, group size, and stocking density on activity in freestall-housed dairy cows. J Dairy Sci 2012;95:3064-9. https://doi.org/10.3168/jds.2011-4953

16. Neave HW, Lomb J, von Keyserlingk MAG, Behnam-Shabahang A, Weary DM. Parity differences in the behavior of transition dairy cows. J Dairy Sci 2017;100:548-61. https://doi.org/10. 3168/jds.2016-10987

17. Miltenburg CL, Duffield TF, Bienzle D, Scholtz EL, LeBlanc SJ. The effect of prepartum feeding and lying space on metabolic health and immune function. J Dairy Sci 2018;101: 5294-306. https://doi.org/10.3168/jds.2017-13481

18.Schirmann K, Chapinal N, Weary DM, Heuwieser W, von Keyserlingk MAG. Rumination and its relationship to feeding and lying behavior in Holstein dairy cows. J Dairy Sci 2012; 95:3212-7. https://doi.org/10.3168/jds.2011-4741

19. Oetzel GR, Emery KM, Kautz WP, Nocek JE. Direct-fed microbial supplementation and health and performance of preand postpartum dairy cattle: a field trial. J Dairy Sci 2007;90: 2058-68. https://doi.org/10.3168/jds.2006-484

20.Coonen JM, Maroney MJ, Crump PM, Grummer RR. Short communication: effect of a stable pen management strategy for precalving cows on dry matter intake, plasma nonesterified fatty acid levels, and milk production. J Dairy Sci 2011;94: 2413-7. https://doi.org/10.3168/jds.2010-3729

21. Vazquez-Anon M, Bertics S, Luck M, Grummer RR, Pinheiro J. Peripartum liver triglyceride and plasma metabolites in dairy cows. J Dairy Sci 1994;77:1521-8. https://doi.org/10. 3168/jds.S0022-0302(94)77092-2

22.Silva PRB, Moraes JGN, Mendonca LGD, et al. Effects of weekly regrouping of prepartum dairy cows on metabolic, health, reproductive, and productive parameters. J Dairy Sci 2013;96:4436-46. https://doi.org/10.3168/jds.2012-6464

23. Herdt TH. Fuel homeostasis in the ruminant. Vet Clin North Am Food Anim Pract 1988;4:213-31. https://doi.org/10.1016/ S0749-0720(15)31045-8

24. Overton TR, Waldron MR. Nutritional management of transition dairy cows: strategies to optimize metabolic health. J Dairy Sci 2004;87(Suppl):E105-19. https://doi.org/10.3168/ jds.S0022-0302(04)70066-1

25. Wu Z, Alugongo GM, Xiao J, et al. Effects of an immunomodulatory feed additive on body weight, production parameters, blood metabolites, and health in multiparous transition Holstein cows. Anim Sci J 2019;90:167-77. https://doi. org/10.1111/asj.13066

26.Sun F, Cao Y, Cai C, Li S, Yu C, Yao J. Regulation of nutritional metabolism in transition dairy cows: energy homeostasis and health in response to post-ruminal choline and methionine. PLoS One 2016;11:e0160659. https://doi.org/10.1371/ journal.pone.0160659

27. Wang B, Wang C, Guan R, et al. Effects of dietary rumenprotected betaine supplementation on performance of postpartum dairy cows and immunity of newborn calves. Animals 
2019;9:167. https://doi.org/10.3390/ani9040167

28. Fustini M, Galeati G, Gabai G, et al. Overstocking dairy cows during the dry period affects dehydroepiandrosterone and cortisol secretion. J Dairy Sci 2017;100:620-8. https://doi. org/10.3168/jds.2016-11293

29. Chebel RC, Silva PRB, Endres MI, Ballou MA, Luchterhand KL. Social stressors and their effects on immunity and health of periparturient dairy cows. J Dairy Sci 2016;99:3217-28. https://doi.org/10.3168/jds.2015-10369

30. Allen MS. Relationship between fermentation acid production in the rumen and the requirement for physically effective fiber. J Dairy Sci 1997;80:1447-62. https://doi.org/10.3168/ jds.S0022-0302(97)76074-0 